\title{
Narrative and Dialogical Reflexivity: An Approach between Writing and Inner Speech
}

\author{
Narrativa e Reflexividade Dialógica: Uma Aproximação \\ entre Escrita e Fala Interna
}

\author{
Flávia Encarnação Motta, Julia Carolina Rafalski, Iasmyn Cerutti Rangel \\ \& Mariane Lima de Souza* \\ Universidade Federal do Espírito Santo, Vitória, Espírito Santo, Brasil
}

\begin{abstract}
This study investigated the presence of dialogical reflexivity indicators in compositions (written texts) and established possible links between those indicators and narrative structures. A group of 23 children, between eight and ten years old, wrote two compositions on the themes "Tell your story" and "How do I talk to myself?". The results suggest that the dialogicality of reflective processes is involved in the writing expression: whereas. The first theme of compositions presented dialogues between the characters (dialogical structure), the second one presented self-talk (direct description of reflective action). In conclusion, it is discussed the relationship between dialogical reflexivity indicators in written texts and the role of the author's reflective process about what he/she writes as the basis for dialogicality.

Keywords: Narrative, reflexivity, writing, inner speech, childhood.
\end{abstract}

\begin{abstract}
Resumo
Este estudo investigou a presença de indicadores de reflexividade dialógica em redações e estabeleceu possíveis relações entre esses indicadores e a estrutura narrativa. Um grupo de 23 crianças, com oito e dez anos de idade, escreveu duas redações com os temas 'Conte sua história' e 'Como eu converso comigo mesmo?'. Os resultados sugerem que a dialogicidade do processo reflexivo está implicada na expressão escrita: enquanto as redações do primeiro tema apresentaram diálogos entre as personagens (estrutura dialógica), as redações do segundo tema apresentaram autodiálogos (descrição direta da ação reflexiva). Para concluir, discute-se a relação entre indicadores de reflexividade dialógica em textos escritos e o papel do processo reflexivo do autor sobre o que escreve como base para a dialogicidade.

Palavras-chave: Narrativa, reflexividade, escrita, fala interna, infância.
\end{abstract}

Reflexivity, as an attribute of the mind to think about itself, is a human particularity (Wiley, 2006) conceived as a reason that it takes a subject to analyze yourself and your attitudes. Also known as 'self', 'sense of self' and 'self-consciousness', reflexivity is the basis of the psychological phenomenon of self, that is, the conscious awareness of one's own conscience, even though aspects of pre-reflective thought to play an important role in this process (Lysaker, 2006). From the perspective of semiotic phenomenology, the conscious experience of self can be understood as a communicative act (DeSouza \& Gomes, 2005; Gomes, 1997), in other words, an act of dialogue that occurs between an addressee and himself/herself in a process that engenders own reflexivity (DeSouza, DaSilveira,

\footnotetext{
* Mailing address: Departamento de Psicologia Social e do Desenvolvimento, Universidade Federal do Espírito Santo, Programa de Pós-Graduação em Psicologia, Av. Fernando Ferrari, 512, Vitória, ES, Brasil 29075-910.

E-mail: flaviaemotta@yahoo.com.br
}

\& Gomes, 2008; DeSouza \& Gomes, 2009). Accordingly, conscious experience of self, dialogue and reflexivity are different aspects of the same phenomenon defined in this study as dialogical reflexivity. The dialogicity, therefore, is the essential quality of this process, and can be defined as a dialogue that is both internal/reflective (consciousness back on itself) and external (consciousness addressing other consciousnesses; DeSouza \& Gomes, 2009).

The narrative, in turn, is a way for the individual to produce a sense of self, establishing relationships between different internal 'voices' which are in constant dialogue (Hermans, 1999). In fact, the narrative is becoming a constant theme of self psychological theorizing, relocating the discussion of the phenomenon in the communication context (DeSouza \& Gomes, 2005). In the developmental psychology area in particular, Oliveira (2006) highlights the importance of dialogical narrativist perspective like an epistemological tendency and relates it to the second cognitive revolution in Psychology and linguistic turn in Philosophy. As a matter of study, narrative finds great 
resonance, therefore, in linguistic and psychological studies, especially the dialogical self framework (Hermans, 2001a, 2001b; Hermans, Kempen, \& Van Loon, 1992), highlighting the notion of dialogicity as a crucial aspect. The dialogical narrativist perspective arises as a promising theoretical model of the development of identity processes in adolescence (Oliveira, 2006) because its power to explain complex phenomena. However, dialogical theory still needs to advance its methodological counterpart, especially with regard to the empirical study of the dialogical self.

In the last two decades, research on dialogicity has related the construct to data obtained from the adult and child inner speech verbalization (Bertau, 1999, 2007; DaSilveira, 2007; DeSouza, 2005; Fogel, Koeyer, Bellagamba, \& Bell, 2002) following, from the developmental psychology perspective, the Vygotsky's pioneering studies (1934/1989) about inner speech. Such studies have focused on the analysis of participants' verbalized inner speech during a problem solving task. Moreover, the findings of DaSilveira (2007) and DeSouza and Gomes (2005) pointed out a list of indicators of dialogic reflexivity in the level of syntactic structure, listing as main sentences the types 'question', 'question-answer', 'assertion-denial', 'exclamation'.

On the other hand, studies on dialogicity in language written form have focused on the analysis of literary texts, following the appointments made for more than eight decades by Mikhail Bakhtin (1895-1975). Bakhtin's work brought a new perspective on language and communication: for him, the word is a bond between 'me' and 'the other' (Floreskaya, 1989). Similarly, we can understand writing as a production made for 'the other', which occurs through internal and external dialogic situations, since it implies a reflection on the part of the author about what he writes, but also implies a reflection about the other who may read what was written. Thus, the central argument of this article is that the written form of language can also express dialogicity. Based on empirical evidence obtained from a study with children in elementary school, we sought to answer (a) if it is possible to identify indicators of dialogicity in compositions of children, (b) what is the nature of these indicators, (c) how these indicators can be identified in written language and (d) if these indicators are related to the narrative structure. More specifically, we wanted to better understand this period of development in which oral language is already established and in which the written language has already been acquired.

\section{Dialogical Reflexivity and Inner Speech}

For Vygotsky (1934/1989) thought comes from people's relationship. He considers language as an element in the study of consciousness forming the subject, and the internalization of speech as an important issue in the process of language development. As for Bakhtin (1929/1984), both thought and the word can be understood as the expression of a dialogue between two different speakers in which dialogue becomes a language element. Communication is a form of human personality existence, and the other is not simply a second interlocutor, but a consciousness that exchange with another consciousness, the later being collective and composed of many people. Thus, in this conception, this is the appropriate dialectic: the addressee sees himself as a person who crosses himself and his activity to others (Floreskaya, 1989). As Bertau (2011), it is in dialogue that language and activity meet themselves.

People develop their reflective consciousness due to dialogical exchanges they have with their caregivers (close people) during childhood, that is, the language learning development process happens in mother-child interactions. So the thought is an internalized dialogue between mother and child. Traces of this dialogue can be seen in the subjective discourse throughout life.

Human relationship is the existence condition for the dialogical perspective. According to Lyra (2005), it is the development of communication as a dialogue that allows us to identify the differentiation of the baby as a dialogical self. The dialogism includes all forms of relationships, among them the process of meaning and knowledge, which is established through the individual subjective experience. Thus, communication generates dialogicity which existence, in turn, depends on human experience that produces it and is produced by it. There are exchanges of meanings in a dialogical relationship, among those who participate in it and, therefore, dialogicity depends on the cultural context.

In a pioneering perspective, Hermans et al. (1992) understand the dialogicity as the basic condition for the self constitution or, in other terms, for the reflective sense of self. Supported by William James (1890/2007) self theory and inspired by Bakhtin's dialogue ideas (1929/1984), dialogicity is explained as a result of the dialogue between the author (I) and actor (me) and as a fundamental pillar of self consciousness. Dialogical relationships occur among different self positions, which can be internal (I as son, I as student, I as father) and external (my father, my teacher, my son). The self multiplicity is a product of social relations or, in other terms, the collective voices embedded in dialogue form. Opposed to the individualistic view of self, the dialogical self proposes that the same person may occupy many self positions, in which he/she may disagree, understand, oppose, contradict, and ask for the 'I' in another position. However, the social notion of self means that other people can occupy different and several voices in an internal dialogue, producing a multivocal self. That is, the 'I' can interpret the other person, can assume other positions alternatively, from the point of view of the real other or even the imaginary other (Hermans, 2001a).

The relationship between dialogical reflexivity and inner speech has been investigated, more recently, both in adults and in children. DaSilveira (2007), in a study of adults' thinking styles, suggests that external sources (social and physical) are reproduced in inner speech, which also produces a distance between the self and mental events experienced, facilitating self-observation. Lidstone, Meins and Fernyhough (2012) indicate that inner speech is a me- 
Motta, F. E., Rafalski, J. C., Rangel, I. C. \& Souza, M. L. (2013). Narrative and Dialogical Reflexivity: An Approach between Writing and Inner Speech.

diator of cognition in children with atypical language development unrelated to specific physical or environmental causes. Another study with intellectually high-functioning adults with autism spectrum disorder (Williams, Bowler, \& Jarrold, 2012) found that although in adults with autism inner speech is not used with the function of planning, it is an important mediator in the short-term memory.

\section{Dialogic Reflexivity, Narrative and Writing}

Similarly to dialogicity, the narrative is a condition inherent to the self because the reflective process of consciousness is arranged and extended in time. From the perspective of the dialogical self theory, the voices that are related within the mind also include external voices, those coming from the point of view of other people about the subject. These positions represented by the other are constructed and reconstructed throughout life (Hermans, 1999). For Oliveira (2006), narratives form a setting for the sense of self, being the context of the temporalities intersection and a permanent tension between the illusion of temporal continuity and the lived, experiential, cyclical, illogical time.

The oral narrative as a form of discursive thought, allows the young child to gradually build his/her self-image, claim Smith and Sperb (2007). The analysis of the development of this narrative allows us to observe how children include information from the external environment. The child assumes the role of narrator when he/she begins to recognize himself/herself as a person, and at the same time assesses what he/she narrates. By telling stories or events, the child strives to sustain a cohesive and constant sense of himself/herself. According to the authors, at this time of development, the child learns to deal with the complex and diverse knowledge he/she has about himself/herself and the world, culture and language. The oral narrative helps the language abstraction adjusting the direction and continuity, which will serve as the basis of the evolution of the reading and writing processes and all school learning.

The emergence of written narrative, in turn, involves a more complex cognitive processing, not just the act of writing. The written intellectual activity demands higher mental process elements such as planning, goal setting and retrieving memories, and also allows for problem solving (Bereiter \& Scardamalia, 1987). The location of events over time allows the start of a pre-construction of the narrative. Narrative writing can reveal, in its course, facts related to personal history: as a past record instrument, the narrator recounts events of this time in his personal history. In the narrative, there may be a projection of the story in the speech that depends on how the author creates situations throughout the text. The autobiography of the writer in particular requires taking a position about himself and about his attitudes to the facts of his own life. This movement of distancing the leading role allows the writer to see himself axiologically, that is, by a value judgment. The creative act is a condition for there to be the voice displacement process: from his voice as a writer, as narrator, as the protagonist in his own story, assuming the role of another character, or creating other roles for himself (Faraco, 2010). According to Guimarães and Vieira (2009), the writing process can generate in the author both internal and external dialogical situations. The first case occurs because the author is confronted with him when tells the facts of his history. The second one occurs because the author is concerned about interlocutor and the need to make himself understood by the text. When writing about himself, the author presents ideas and can produce direction in a dialogical exchange with him and the interlocutor.

Therefore, we can understand that dialogical reflexivity and narrative form a virtuous cycle, in which each aspect helps and is helped by another. However, considering written production, dialogue and narrative can characterize different discursive structures. The dialogical structure (characterized by the alternation of the people in the speech) and narrative (characterized by action predicates and the temporal organization of events) would be two types of textual discourse genre, set in a total of six (Silva, 1997). Besides these two, Silva (1997) lists four other structures: descriptive (characterized by predicates related to entities); expository/argumentative (propositions with complex syntactic constructions and hypothetical constructions); procedural (characterized by impersonality and verbs in the imperative, future or infinitive), expressive (characterized by predicates with the opinion verb and a predominance of the first person singular). Thus, dialogical reflexivity could be easily identified in the written production, varying according to the discursive structure of the text: the dialogical text types would naturally present more dialogicity indicators than narrative. The goal of this study was to identify and describe the possibilities of expressing dialogical reflexivity in the writing of 8 to ten years old children, from the comparison between two text styles, with different discursive structures.

\section{Method}

This is a qualitative approach, characterized as descriptive according to its goals, following the criteria of semiotic-phenomenological analysis (Gomes, 1998; Lanigan, 1988). The study was approved by the ethics committee on human research regularly recorded in CONEP (National Council on Ethics in Research). The head of the school and the parents signed a Term of Consent by accepting to participate.

\section{Participants}

The study included 23 participants, 10 children at the age of eight and 13 at the age of 10, male and female, students from the third and fifth year of elementary school from a public school in the City of Vitoria, State of Espírito Santo, Brazil, from low social and economic level. The sample inclusion criteria were: (a) to be literate; (b) to be eight or ten years old; (c) to be at the third or fifth 
year of primary school; (d) to have no complaints about learning disability according to the school teacher; (e) to have parental consent to participate.

\section{Instruments}

We used the two protocols below, developed specifically for the research:

Composition Protocol 'Tell your history' with the illustration of a child accompanied by a thought bubble, inside which the same picture is shown. There are two versions of the child: first, wearing a dress and long hair for girls, and in the second, wearing a T-shirt and shorts and with short hair for boys.

Composition Protocol 'How do I talk to myself?', with a brief statement next to the child illustration (also in two versions, as the first instrument) before a school desk, accompanied by a thought bubble, within which an internal dialogue is described referring to the resolution of a problem. The statement is as follows: "Joana is a girl who is your age. She goes to school and likes to play. One day, she needed to solve a math problem and began talking to herself..." In the version for boys, Joana is replaced by João.

\section{Procedure of Data Collection}

The collection of compositions was held over two days with a one-week interval between them, as part of routine classroom, at a time previously agreed with the school. On the first day of collection, the children were informed about the study and received the Composition Protocol 'Tell your story'. In the next week, the children received the Composition Protocol 'How do I talk to myself?'.

After composition production, the teacher responsible for the students informed the researcher which students met the criteria outlined above for inclusion in the sample of their composition and the others were excluded. The compositions received a code to protect the identity of participants and facilitate the organization of the data: in pairs (two compositions each child) were named ' $\mathrm{C}$ ' followed by a number (01 to 23). Participants $\mathrm{C} 01$ through $\mathrm{C} 10$ of eight years old make up the first group (G1); participants C11 to $C 23$, of 10 years old make up the second group (G2).

\section{Procedure for Data Analysis}

The Composition Protocol 'Tell your story' provided data about the narrative elements, and were analyzed in two aspects:

1. Thematic context, following semiotic-phenomenological analysis' criteria (Gomes, 1998) and,

2. Textual-discursive types segmented into three levels (Silva, 1997), namely (a) discursive structure (narrative, descriptive, expository/argumentative, procedural, expressive dialogue), (b) communicative function (code, receiver, addressee, channel) and (c) communicative intent (phatic, conative, emotive, metalinguistic, descriptive). The Compositions Protocol 'How do I talk to myself?' provided data on dialogical reflexivity indicators and were categorized according to the criteria defined in DaSilveira (2007), DeSouza et al. (2008), and DeSouza and Gomes (2005) as well as those that emerged from the compositions. Both data sets were analyzed by three judges (two psychology undergraduate students and the researcher) independently after training to understand the criteria previously determined. All writings who had not obtained the agreement of three judges were excluded. After this selection, the reflexivity indicators identified were counted. A qualitative comparison between the narratives elements in compositions 'Tell your story' and dialogical reflexivity indicators in compositions 'How do I talk to myself?' followed the part-whole logic of relationship, based on the criteria of semiotic phenomenology, in its reflective three steps: description, reduction and interpretation (Gomes, 1998). The phenomenological description specifies the thematic context of the phenomenon studied. The phenomenological reduction defines the problematic focus. The phenomenological interpretation clarifies the essence of the phenomenon investigated.

\section{Results}

A phenomenological description of the results was divided into three parts called, respectively, 'Narrative Elements: Tell your story', 'Dialogical reflexivity indicators: How do I talk to myself?' and 'Comparison between the narrative elements and dialogical reflexivity indicators'. The difference between the participants of group 1 and 2 was very specific, so such distinctions are described at the end of each part. The participant's names are purely fictitious in order to preserve their anonymity.

\section{'Narrative Elements: Tell your Story'}

The compositions presented a diversity of thematic contents, revealing facts relating to the personal stories of the participants. The recurrent issues in the texts were self-presentation (general data description identification such as name and age); physical self-description (focusing on characteristics such as skin color, eyes, hair and height) and emotional (happy, lazy, playful, anxious, timid, 'best', 'house star', prankish, impatient, intelligent); daily activities (walking, family day, jokes, routines at home and at school); personal preferences for people and food; events (birthday parties, family gathering); their own birth and birth of brothers and sisters; and the facts about the choice of their name.

The stories were narrated as in the first person singular as in the third person singular, occurring including the juxtaposition of the two perspectives on the same composition as in the following examples (excerpts did not suffer any kind of correction): "There was once a boy who was alone and spent time and got 5 more friends and they were 
Motta, F. E., Rafalski, J. C., Rangel, I. C. \& Souza, M. L. (2013). Narrative and Dialogical Reflexivity: An Approach between Writing and Inner Speech.

playing soccer . . . then they went away and I was playing video games" (C19). "My mother said - stops running, you will fall, takes care" (C06).

Other personages (parents, grandparents, brothers and sisters, cousins, friends and teachers) were part of the shares with the author-person (who writes the work):

One day I was playing in the yard, then I saw a bunch of ants coming under the earth. I called my grandmother and two of us we got home and took a magnifying glass when we look at the ants they were very large we saw the antennae and the tusks of them with easily. (C17)

And without the author-person: "There was once a man and a woman. One day the woman became pregnant. On the day the child was born..." (C01).

The narrative time stood between internal (or psychological) and social, once were revealed both autobiographical aspects of the authors and aspects of the environment, including other people. "I'm Joana I'm a child I like to play ball I like my mother and my father" (C04).

Regarding the type textual-discursive, the first level of analysis identified four types of discourse structure:

1. The narrative, composed by the presence of action predicates and the temporal organization of events;

2. Descriptive, characterized by predicates related entities;

3. Expressive, characterized by predicates with the opinion verb and by a preponderance of the $1 \mathrm{st}$ person singular and

4. The dialogue, which is characterized by the alternation of the people in the speech. From the analysis of the judges, the latter category was subdivided into (a) dialogical structure with a score of dialogue and (b) dialogical structure without the punctuation of dialogue. There was a junction of two or more forms in the same wording.

My story begins I was born in my mother's womb, so the doctor consider myself (sic) as a giant baby, because I was the largest medical [at hospital] (narrative structure) I'm like being the star of the house. I'm a bit lazy. I am funny and sometimes playful (sic) (descriptive structure) I like hanging out with my parents very much, they buy almost all I ask. And speak and do (sic) what I think. I do not like people lying (expressive structure). (C10)

"So I said I was distracted by my cousin, there was a concrete near a sand" (dialogical structure without the punctuation of dialogue; C15).

"I really like animals and I say: - When I grow up I want to be a veterinarian because I love animals!' (Dialogic structure with a score of dialogue; C23).

There was a predominance of two types of narrative structure of the G1 participants, and it was observed the repetition of expressive structure combined with descriptive, narrative or dialogical. On the other hand, G2 participants showed the junction of two or three structure types with another type presents in all these combinations, then the dialogue structure.
The second level of analysis identified writing as the code used and the readers of the text, in this case, the researcher, the classroom teacher and educational advisor as the receivers. From the participants' perspective, the receivers can be characterized as virtual recipients once children (adressees) had more than one person to whom to address your writing. However, the recipient is also a superior recipient because participants had, at the same time, the notion of possible readers-receivers and may assume how they would be their responsive understanding. Once suggested as an instrument of the study, the communication channel was the composing of composition.

The third level of analysis identified four different types of communicative functions: (a) the conative function, when the participant referred to facts of everyday life: " $O n$ Monday I go to school early in the morning and study a lot. When the signal hits, I go to the playground and I eat I'll play ball ..." (C20), (b) the emotive function, when the participant issued a feeling or opinion: "In this paper I will tell my story. . . I was crying and my mother's eyes filled with water pity to leave me crying" $(\mathrm{C} 13),(\mathrm{c})$ the phatic function, when the participant began wording, drawing the reader's attention to the statement: "Hi I'm João I am 10 years old" (C20), and (d) a descriptive function, when the participant offered a description of himself or the environment: "I'm so kind of student and very good and very gentle and studious" (C03).

Dialogical Reflexivity Indicators: 'How do I Talk to Myself?'

The compositions presented three types of dialogical reflexivity indicators: (a) indirect description of the dialogical reflexive action, (b) direct description of dialogical reflexive action, subdivided into subcategories 'affirmation', 'exclamation', 'phatic function', 'imperative', 'question', 'question and answer', 'moral reflection or existential doubt', 'logical reasoning', 'action description' (c) denial of reflective action characterized as conversation with himself. In addition to these indicators, meaningful utterances were classified in a fourth category called 'others', but that were not part of any of the three categories above.

Indirect Description of Dialogical Reflexive Action. This category suggests a dialogical reflexivity already mediated by consciousness, in which inner speech is perceived by the participant, but not expressed in writing as dialogue. It is characterized by temporality, focusing on present, past or future actions and facts. Reflexivity targeted for the future includes statements that express the possibilities of something happening at a time near or distant future: "I think what might happen and what will happen. I imagine now that the playground will be very cool" (C01). Reflexivity directed to this includes statements that describe self-perceived reflexive act, putting the thought in here/now: "I think when I play I think and I speak with myself that I have also played around thinking" (C03), "I talk when I answer matters, when I go home. When I watch TV I also speak alone" (C08). Reflexivity directed at past events include the statements that describe 
a significant event has occurred: "I spoke to me: I am a good student" (C02).

Direct Description of Dialogical Reflexive Action. This subcategory indicates an ongoing inner speech, by alternating of participant between different speech being (I and me; narrator-author and person-author, author and reader). It includes statements in the dialogues form, in which interaction emphasizes the communicative aspect of dialogical reflexivity. The subcategory 'affirmation' includes statements that express affirmation of an idea or thought about himself, and may also be related to a belief: "I think when I make accounts" (C16). The subcategory 'exclamation' includes statements that express surprise, conquest or a feeling, "I won, I won, I won" (C07), "Gee, how many thoughts I have!" (C10). The subcategory 'phatic function' includes statements that represent the beginning of a dialogue, a presentation or a reminder: " $\mathrm{Hi}$ ! I have 8 years old..." (C09). The subcategory 'imperative' includes statements that clearly express an order or command to himself: "I was not sure so I said to myself I'm going to sleep" (C18). The subcategory 'question' includes statements that express an isolated issue with no answer and can express doubt between two or more factors, "I said to myself: I like to dream myself?" (C02); "Will it be cool [?] Is it this or that result [?] Why is study complicated [?]" (C13). The subcategory 'question and answer' cover statements that express a question then answer: "Did something bad will happen [?] Will happen a good thing [!] Then I'm calm" (C13). The subcategory 'moral reflection or existential doubt' corresponds to statements that generate reflection on complex issues: "How God was born? Why leaves are green and not pink? Why formerly white peoples mistreated black people just because they were black?" (C10). The subcategory 'logical reasoning' includes utterances directed to a problem resolution. "How much is 20 and 24 years old together? I like a friend who is 10 years old, if I add with my age it was 20 years" (C09), "I thought well if I stay calm, relax I can try several times because the game will not walk away" (C17). The subcategory 'action description' includes statements that represent speech directing or describing an action: "Now I'm thinking in mind, now is less. I just. Now I will show the teacher" (C15).

Denial of Reflexive Action While Dialogue with Himself. This category includes definitions or stereotypical perceptions of the situation to talk alone, for example, as a 'crazy' person attitude (sic). "I don't talk alone, but I talk to my parents" (C04), "I don't talk alone but I talk to people" (C19). First researcher' field daily records indicate that participants, authors of these compositions, argued orally do not talk about themselves, expressing an understanding that would require the presence of a real person for that dialogue was established.

Others. This subcategory includes inferential thinking indicators and/or self-monitoring in learning: "I only talk about the duty but teacher thinks we're kidding" (C06). "Now there is a time that I have a difficult word to say and
I'm talking about it, so the woman's name was Claudete and I was talking: Claudete, Claudete, Claudete ..." (C07).

\section{Comparison between the Narrative Elements and} Dialogical Reflexivity Indicators in Groups 1 and 2

In compositions 'Tell your story' dialogical textual type was identified only in G2, combined textual narrative type. It should be noted, however, that the researcher was not explicit about dialogue in wording instructions. In compositions 'How do I talk to myself?' dialogical reflexivity indicators type action reflexive indirect description appeared as in G1 as G2. However, the dialogical reflexivity indicators type reflective action direct description was predominant in $\mathrm{G} 2$.

The textual-discursive dialogical type (presence of dialogue) of compositions 'Tell your story' appeared related to a predominance of dialogical reflexivity indicators type direct description reflexive action (presence of self-dialogue) in compositions 'How do I talk to myself ?'. This relationship appeared only in G2 compositions.

\section{Phenomenological Reduction}

The phenomenological description presented the thematic context of the studied phenomenon in which established a relationship between the elements of the narrative ('Tell your story') and indicators of dialogic reflexivity ('How do I talk to myself?'). This relationship expresses the convergence between type-textual discursive dialogical and direct description of reflective action in compositions of 10 years old children, specified the problematic focus: the dialogic quality of the reflective process is revealed in written expression as the child enhances its linguistic-grammatical competence and develops your self-consciousness.

\section{Discussion}

\section{Phenomenological Interpretation}

The process of remembering and reflecting about events of our own life and narrate them through written expression enables the organization and reorganization of history when we are writing an autobiography. A person who tells the story assumes the active roles of writer and character of the text, which may explain the development of dialogues situations between characters identified in the participants' compositions. So the author puts aside his own speech when he ascribes speech to the characters, since the statements do not belong him anymore. Likewise, the presence of characters related to family, friends and teachers in compositions confirm an important assumption of the dialogical self theory: the notion that the relationship among different voices within mind also includes the point of view of others (Hermans, 2001b).

The writer must not only offer a description about himself in an autobiography. For Bakhtin (cited by Faraco, 2010), the creator-author, even if it is the writer-voice, shall move out of the text. Assuming active roles, the many voi- 
Motta, F. E., Rafalski, J. C., Rangel, I. C. \& Souza, M. L. (2013). Narrative and Dialogical Reflexivity: An Approach between Writing and Inner Speech.

ces present in composition came from this strolling through other viewpoints. At that moment came the dialogue, which is more than a conversation among entities described, but the actual switching of roles, positions and statements, which are built with others. The theme 'Tell your story' seems to have favored not only the first-person narrative, but the development of self-presentation, and also the fact that the time of the narrative have been located between the internal (expressing thoughts, ideas, feelings) and external (describing environments).

The emotional theme of the compositions was positive, despite the socioeconomic conditions of children. Despite living in neighborhoods with a population in poverty and exposed to violence, children seem to have a good resilience. This positive coping is possibly explained by the pedagogical work developed in school: there is a concern about bringing the family and the community for their activities, enabling rich and varied interactions and providing students with positive school experiences. The pedagogical proposal may have provided an education that favored the awareness, on the part of students, of their own mental processes and assisted the self-reflection and self-observation development. This pedagogical work possibly partly explains the presence of direct indicators of reflective action in written composition.

In compositions 'How do I talk to myself?', the presence of an indirect description of dialogical reflexivity with a past-present-future temporal structure can be explained by the temporal nature of the narrative structure that enables the construction of a story and an identity by subject. As Hermans (2001b), the self can be understood as a narrative because it is also organized and extended in time. Therefore, the narrative itself exists because of the time factor; in other words, need to be structured in the course of time to exist.

When describing the conversation they have with themselves, children could withdraw from that moment and see themselves. In this position face to face and in a dialogue, either as author or as character, they are engaged in a reflective process that provides and is provided by questions, remembering and even solving problem.

The dialogical reflexivity evidenced in writing by statements that suggested dialogues of the author with himself in alternating roles (for example, to question themselves, to repeat the mother or brother speech, to infer what the teacher was thinking) and their with the receiver, when considering who would read the text (for example, when used phatic function) is possibly an outcome for writing process. That is, the writing provides access, at any time, to addressee's information, since addressee and receiver are the same. Thus, it is possible that the written narrative has favored the monitoring of the multiples I-positions, and a consequent self reorganization, to allow the redefinition of values and therefore a new way of thinking and acting. In telling their life as a story, the children took the active role of writer and character of their own text and could see themselves through the eyes of other characters. The process of story narration shifted the creators-authors of the text by placing them in active roles. This movement gave voices to the characters and the narrative became more than a self-description, as the authors have had the possibility of taking other perspectives about themselves.

The difference between the children in G1 and G2 with respect to the presence of dialogical reflexivity indicators in writing can be explained by the development of the consciousness reflective process. As Morin (2012), self-consciousness tends to be increased by inner speech mutually. Similarly, Hermans (2001b) points to self-reflection as a cause of the development of a metaposition, which is the ability of the self to stand at a point equidistant as a mediator between the various positions it occupies. Therefore, it can be suggested that the metaposition is more developed in children 10 years old compared to eight years old. That is, the older children may be more self-conscious since experienced inner speech longer, are more aware of themselves and thus better able to utilize the dialogical structure by writing.

\section{Final Remarks}

The results of this study emphasize the importance of using expressive writing as empirical tool for dialogical reflexivity investigation. Besides allowing narrative construction of personal experiences, writing also enables the participant's creativity expression, offering a very rich way to record access to this kind of variable; at first, difficult to reach by another evaluation's instrument. The findings also helped us to understand how the reflective process of consciousness relates to the language development. It seems very clear that oral reflexivity feeds written reflexivity and, then, the later influences the first one.

Finally, it is hoped that this research will stimulate and aid future studies on the dialogical reflexivity development. Replications in a different social and economic context, comparing schools and also pedagogical projects, could be particularly relevant for a more detailed understanding of the influence of school on children's cognitive development. Another suggestion for future studies is to investigate the relationship between oral and written dialogical reflexivity indicators from a longitudinal perspective. Although the inner speech internalization process and its influence on thought are well known to psychologists and pedagogues, a larger study, following the dialogical reflexivity oral and written expression, beginning in the writing acquisition phase and end in adolescence, would provide important clarifications on the development of this process.

\section{References}

Bakhtin, M. M. (1984). Problems of Dostoevsky's poetics. Minneapolis, MN: University of Minesota Press. (Original work published 1929)

Bereiter, C., \& Scardamalia, M. (1987). The psychology of written composition. London: Lawrence Erlbaum. 
Bertau, M. C. (1999). Spuren des Gespraechs in innerer sprache Versuch einer analyse der dialogischen anteile des lautes denkens. Zeitchrift für Sprache \& Kognition, 18(1-2), 4-19.

Bertau, M. C. (2007). On the notion of voice: An exploration from a psycholinguistic perspective with developmental implications. International Journal for Dialogical Science, 2 , 133-161. Retrieved from http://ijds.lemoyne.edu/journal/2_1/ index.html

Bertau, M. C. (2011). Dialogue: Where language meets activity. International Journal for Dialogical Science, 5(1), 17-36. Retrieved from http://ijds.lemoyne.edu/index.html

DaSilveira, A. C. (2007). Conversação interna: Entre a reflexividade e a ruminação (Dissertação de mestrado, Programa de Pós-Graduação em Psicologia, Universidade Federal do Rio Grande do Sul, Porto Alegre, RS, Brasil).

DeSouza, M. L. (2005). Self semiótico e self dialógico: Um estudo do processo reflexivo da consciência (Tese de doutorado, Programa de Pós-Graduação em Psicologia, Universidade Federal do Rio Grande do Sul, Porto Alegre, RS, Brasil).

DeSouza, M. L., DaSilveira, A., \& Gomes, W. B. (2008). Verbalized inner speech and the expressiveness of self-consciousness. Qualitative Research in Psycology, 5(2), 154-170.

DeSouza, M. L., \& Gomes, W. B. (2005). Aspectos históricos e contemporâneos na investigação do self. Memorandum, 9, 78-90.

DeSouza, M. L., \& Gomes, W. B. (2009). Temporalidade e espacialidade na estrutura do self nas abordagens semiótica e dialógica. Psicologia em Estudo, 14(2), 365-373.

Faraco, C. A. (2010). Autor e autoria. In B. Brait (Ed.), Bakhtin: Conceitos-chave (pp. 37-60). São Paulo, SP: Contexto.

Floreskaya, T. A. (1989). Psychological problems of dialogue in light of the ideas of M. M. Bakthin and A. A. Ukhtomskii. Soviet Psychology, 27(5), 29-40.

Fogel, A., Koeyer, J., Bellagamba, F., \& Bell, H. (2002). The dialogical self in the first two years of life. Theory and Psychology, 12(2), 191-205.

Gomes, W. B. (1997). A entrevista fenomenológica e o estudo da experiência consciente. Psicologia USP, 8, 305-336.

Gomes, W. B. (Ed.). (1998). Fenomenologia e pesquisa em Psicologia. Porto Alegre, RS: Editora da Universidade Federal do Rio Grande do Sul.

Guimarães, P., \& Vieira, N. M. (2009). Bakhtin: Na análise literária e na Psicologia Social [Resumo]. In Anais eletrônicos XV Encontro Nacional da Abrapso. Maceió, AL: Associação Brasileira de Psicologia Social. Recuperado em 20 de setembro, 2011, de http://www.abrapso.org.br/siteprincipal/images/ Anais_XVENABRAPSO/238.bakhtin.pdf

Hermans, H. J. M. (1999). Self-narrative as meaning construction: The dynamics of self-investigation. Journal of Clinical Psychology, 55(10), 1193-1211.

Hermans, H. J. M. (2001a). The dialogical self: Toward a theory of personal and cultural positioning. Culture \& Psychology, 7(3), 243-281.

Hermans, H. J. M. (2001b). The construction of a personal position repertoire: Method and practice. Culture \& Psychology, 7(3), 323-365.

Hermans, H. J. M., Kempen, H. J. G., \& Van Loon, R. J. P. (1992). The dialogical self: Beyond individualism and rationalism. American Psychologist, 47(1), 23-33.

James, W. (2007). The principles of psychology. New York: Cosimo Classics. (Original work published 1890).

Lanigan, R. (1988). Phenomenology of communication: Merleau-Ponty's thematics in communicology and semiology. Pittsburgh, PA: Duquesne University Press.
Lidstone, J. S. M., Meins, E., \& Fernyhough, C. (2012). Verbal mediation of cognition in children with specific language impairment. Development and Psychopathology, 24, 651-660.

Lyra, M. C. D. P. (2005). O modelo EEA para investigação da emergência e desenvolvimento da comunicação e do self: Bases conceituais e fundamentos teórico-metodológicos. Estudos de Psicologia (Natal), 11(1), 25-33.

Lysaker, J. T. (2006). "I am not what I seem to be". International Journal for Dialogical Science, 1, 43-45. Retrieved from http://ijds.lemoyne.edu/index.html

Morin, A. (2012). Inner speech. In V. S. Ramachandran (Ed.), Encyclopedia of Human Behavior (pp. 436-443). San Diego, CA: Academic Press.

Oliveira, M. C. S. L. de (2006). Identidade, narrativa e desenvolvimento na adolescência: Uma revisão crítica. Psicologia em Estudo, 11(2), 427-436.

Smith, V. H., \& Sperb, T. M. (2007). A construção do sujeito narrador: Pensamento discursivo na etapa personalista. Psicologia em Estudo, 12(3), 553-562.

Silva, V. L. P. (1997). Forma e função nos gêneros de discurso. Alfa Revista de Linguística, 41, 79-98.

Vygotsky, L. (1989). Pensamento e linguagem. São Paulo, SP: Martins Fontes. (Original publicado em 1934).

Wiley, N. (2006). Inner speech as a language: A saussurean inquiry. Journal for the Theory of Social Behaviour, 36(3), 319-341.

Williams, D. M., Bowler, D. M., \& Jarrold, C. (2012). Inner speech is used to mediate short-term memory, but not planning, among intellectually high-functioning adults with autism spectrum disorder. Development and Psychopathology, 24, 225-239.
Recebido: 13/12/2011

$1^{a}$ revisão: $12 / 07 / 2012$

$2^{a}$ revisão: $11 / 09 / 2012$

Aceite final: $21 / 09 / 2012$ 